\title{
AULA DE LEITURA: (INTER)AÇÕES E (DES)ENCONTROS
}

A. C. SANTOS
Universidade Federal de Alagoas
adricavalcanti@cedu.ufal.br
Submetido $20 / 07 / 2017$ - Aceito $20 / 04 / 2018$
DOI: $10.15628 /$ holos. 2018.6129

\section{RESUMO}

Este artigo, objetiva refletir sobre o lugar das práticas de leitura no ensino médio da Educação de Jovens e Adultos, no contexto de uma didática da leitura que favoreça o diálogo autor-texto-leitor-mundo. Para isso, desenvolvemos uma investigação qualitativa e do tipo colaborativa, que nos possibilitou identificar quais textos e práticas de leitura são mais recorrentes nas aulas de Língua Portuguesa, de modo a ponderarmos acerca do lugar da leitura no contexto pesquisado. Como aporte teórico dialogamos com
Antunes (2003), Bakhtin (2009), Geraldi (1986; 2010), Larrosa (2013; 2014), Marcuschi (2008), Petit (2010), Koch e Elias (2006). Os resultados mostram que há uma recorrência de práticas de leitura na escola, embora se faça necessário entendê-la como construtoras se sentidos pelo leitor, e possibilitar um diálogo maior com a diversidade de gêneros textuais que circulam nas práticas sociais, assumindo-se o desafio de pensarmos no desdobramento de uma didática da/para leitura.

PALAVRAS-CHAVE: Leitura, educação de jovens e adultos, didática.

\section{READING PRACTICES: (INTER)ACTIONS AND (DES)MEETINGS}

\begin{abstract}
This article aims to reflect on the place of reading practices in the high school of Youth and Adult Education, in the context of a didactics of reading that favors the author-text-reader-world dialogue. For this, we developed a qualitative and collaborative research that enabled us to identify which texts and reading practices are most recurrent in Portuguese Language classes, in order to consider the place of reading in the researched context. As a theoretical contribution, we spoke with Antunes (2003), Bakhtin (2009), Geraldi (1986; 2010), Larrosa (2013; 2014), Marcuschi (2008),
\end{abstract}

Petit (2010), Koch and Elias (2006). The results show that there is a recurrence of reading practices in the school, although it is necessary to understand them as constructors of sense for the reader, and to enable a greater dialogue with the diversity of textual genres that circulate in social practices, assuming the challenge To think about the unfolding of a didactics of and for reading.

KEYWORDS: Reading, youth and adult education, didactics. 


\section{PRIMEIRAS PALAVRAS}

A experiência é algo que (nos) acontece e que às vezes treme, ou vibra, algo que nos faz pensar, algo que nos faz sofrer ou gozar, algo que luta pela expressão, e que às vezes, algumas vezes, quando cai em mãos de alguém capaz de dar forma a esse tremor, então, somente então, se converte em canto. (Larrosa, 2014, p. 10)

A curiosidade epistemológica em investigar as práticas de leitura na Educação de Jovens e Adultos (EJA), desta vez, num campo ainda pouco explorado - no Ensino Médio (EM), adveio de outras experiências de investigações (Santos, 2014; 2017), as quais nos possibilitaram, por meio da interface entre o ensino da Língua Portuguesa (doravante LP) e a formação continuada do professor, encontrarmos uma seara de possibilidades de adentrar na aula, enquanto acontecimento (Geraldi, 2010). E, como inferimos na epígrafe de Larrosa, essas experiências de pesquisas, transformam-se em cantos e fomentam outras inquietações científicas que atravessam o tempo e o espaço, "e ressoa em outras experiências e em outros tremores e em outros cantos" (Larrosa, 2014, p.10).

As discussões que apresentaremos, neste artigo, partem da análise dos resultados do projeto de pesquisa: "Leitura no ensino Médio na Educação de Jovens e Adultos: lugares, reflexões e encontros ${ }^{1 "}$. O referido projeto teve como indagação de base: qual o lugar da leitura nas aulas de Língua Portuguesa no Ensino Médio da Educação de Jovens e Adultos? E, objetivou analisar o lugar das práticas de leitura em uma turma de Ensino Médio da Educação de Jovens e Adultos, no contexto das aulas de Língua Portuguesa. Metodologicamente, desenvolvido por meio de uma investigação qualitativa, do tipo colaborativa (Ibiapina, 2008).

Para a formação do leitor autônomo, por meio de leituras significativas, produções de significados, construções de leitores e de suas histórias de leitura, implica o acesso a uma escola em que há lugar para práticas curriculares de leitura. A propósito da questão sobre o lugar da leitura e do leitor no ensino médio da EJA é relevante pensar a didática da leitura na escola, que segundo Antunes (2003, p. 27), entre outras práticas, ainda é "uma atividade de leitura sem interesse, sem função, pois aparece internamente desvinculada dos diferentes usos sociais que se faz da leitura atualmente". Reafirmando ainda que temos: "uma escola sem tempo para a leitura" (p. 28). Uma escola sem espaço e tempo para a leitura parece paradoxal à medida que essa instituição é, por excelência, o lugar privilegiado para a vivência dessa prática curricular.

Ao entendermos a didática da leitura, como ação e reflexão sistemática sobre o processo de ensino e aprendizagem da leitura, ato pedagógico, enquanto acontecimento, na aula e em práticas socais, defendemos uma escola em que nos eventos e práticas de leitura, vivenciadas pelos alunos, considere: suas leituras prévias, suas histórias de leitura e suas significações produzidas no ato de ler, como condição do trabalho pedagógico de ensino leitura.

\footnotetext{
${ }^{1}$ O referido projeto contou com a colaboração da aluna Larissa Gabriela Gouveia dos Santos. Na ocasião, bolsista Bibic/UFAL (2016-2017).
} 


\section{2 (INTRE)LAÇAMENTO DA PESQUISA: CAMINHOS COLABORATIVOS}

A investigação, de base qualitativa, desenvolveu-se em uma escola pública estadual, situada na cidade de Maceió-Alagoas, especificamente, em 1 (uma) turma do 4o (quarto) período, do Ensino Médio da EJA, durante o período 2016-2017. O sujeito principal da pesquisa, constituiuse de uma professora de Língua Portuguesa, que tinha, à época, 20 (vinte) anos de experiência profissional docente, mas atuava há apenas 1(um) ano no Ensino Médio da EJA.

Adotamos como abordagem metodológica a pesquisa colaborativa (Ibiapina, 2008), que nos permitiu vivenciar ao longo da investigação estratégias metodológicas (Bogdan \& Biklen, 1994) que nos aproximasse do fenômeno investigado, de forma que o objeto e o método de investigação mantivessem uma relação estreita entre as estratégias metodológicas: entrevista, observação da prática de ensino da leitura, sessão reflexiva ${ }^{2}$, sessão de estudo ${ }^{3}$ e grupo focal, realizado com os alunos. Apoiando-nos em Bakhtin (2009) podemos dizer que viver esta investigação, no lócus da escola, significou participar de um diálogo, interrogar, escutar, responder, concordar e, até certo ponto, contribuir para a desconstrução de uma cultura docente (Santos, 2017). Pois, "um enunciado deve ser considerado, antes de tudo, como resposta a enunciados anteriores no interior de uma esfera dada [...]: ele os refuta, os confirma, os completa [...]" (Bakhtin, 2009, p. 298).

No processo de coleta de dados, percebemos que o significado é de importância vital na abordagem qualitativa (Bogdan \& Biklen, 1994). No entanto, os primeiros contatos com a professora e as observações acerca da didática da leitura, ao levar-nos à fonte direta de dados, despertou-nos o interesse mais pelo processo, ou seja, como a leitura é ensinada, do que simplesmente pelos resultados ou habilidades construídas pelos alunos. Pois, as observações das aulas e os diálogos com a professora, mostrou-nos a relevância de se refletir sobre a prática curricular docente no lócus da escola.

Como se trata de uma investigação colaborativa (Ibiapina, 2008), as reflexões não aconteceram apenas sobre as práticas curriculares observadas em sala de aula, mas também em momentos específicos nas sessões reflexivas, entendendo a totalidade que envolve as práticas no ato de educar sujeitos ${ }^{4}$. Pois, como nos indica Ibiapina (2008), o processo reflexivo consiste justamente na possibilidade de os professores, em formação, poderem repensar e modificar seus

\footnotetext{
${ }^{2}$ As sessões reflexivas, como vivenciamos ao longa da investigação, podem ser realizadas com a finalidade de promover encontros destinados a estudos, a reflexão interpessoal e intrapessoal e a análise da prática. (Ibiapina, 2008).

${ }^{3}$ Estudamos com a professora partícipe da investigação as seguintes temáticas: concepções de Linguagem; gêneros e tipos textuais; leitura e práticas discursivas; e leitura e compreensão.

${ }^{4}$ Ao se falar de sujeitos tratamos de um ser Humano, aberto a um mundo, portador de desejos, em relação com outros seres humanos (também sujeitos); um ser social que nasce e cresce em uma família (ou em um substituto de família), que ocupa uma posição em um espaço social, que será inscrito em relações sociais; e ainda um ser singular, exemplar único da espécie humana, que tem uma história, e que interpreta o mundo, dá um sentido a esse mundo, à posição que ocupa nele, às relações com os outros, à sua própria história e a sua singularidade (Charlot, 2001, p.33).
} 
objetivos a partir de discussões sobre o processo ensino-aprendizagem nos contextos de pesquisas.

\section{ENSINO DA LEITURA E ORIENTAÇÕES CURRICULARES: (DES)CAMINHOS NA EJA}

Em Alagoas, nosso lócus de investigação, não encontramos orientações curriculares para o ensino de Língua Portuguesa no Ensino Médio da EJA. Os professores da Rede Estadual, da referida modalidade, afirmaram que consultam os Parâmetros Curriculares Nacionais do Ensino Médio (PCNEM) de 1999 e/ou as Orientações Curriculares Nacionais para o Ensino Médio de 2004, com vista à compreensão de como ensinar a Língua Portuguesa. Sem uma orientação curricular oficial, a professora ${ }^{5}$ partícipe da investigação afirmou: "trabalho com o quê eles [alunos] precisam", levando-nos a questionar quais saberes os alunos deveriam dominar com relação à aprendizagem da Língua Portuguesa, enquanto Língua Materna, na escola.

A Secretaria de Estado da Educação e do Esporte de Alagoas (SEEE) organizou as orientações para implantação e implementação do ensino fundamental e do ensino médio na modalidade da educação de jovens e adultos, a partir de 2012, por períodos letivos semestrais, conforme o art. 3으, da Resolução CEE/AL no 18/2002, e do art. 23, da LDB no 9.394/96. A partir dessas orientações o Ensino Médio da EJA, organiza-se em 2 anos letivos, correspondendo a 4 (quatro) períodos semestrais. Cada ano letivo deve ser ofertado com uma carga horária mínima de 1600 horas/aulas. Assim, nas escolas públicas de Alagoas, o ensino de Língua Portuguesa no Ensino Médio abrange uma carga horária de 52 horas por período letivo, distribuídas em três aulas semanais.

Dado o contexto, faz-se necessário olhar para o lugar do ensino da leitura, na referida modalidade, entendendo que a didática da leitura, entre outros aspectos, pressupõe: escolhas teórico-metodológicas, adesão a uma concepção de língua e de linguagem, de texto e de leitura, além da mobilização de saberes docentes (Tardif, 2002).

Sobre a especificidade do sujeito da EJA, segundo a Resolução no 4, de 2010, do CNE/CEB, no art. 11, § 3으. os cursos em tempo parcial noturno devem estabelecer metodologias adequadas às idades, à maturidade e às experiências de aprendizagens, para atenderem aos jovens e adultos em escolarização no tempo regular ou na modalidade da EJA. Tudo isso impõe ao professor, na aula de leitura, considerar o leitor (aluno) enquanto sujeito que possui conhecimentos enciclopédicos ou de mundo, conhecimento linguístico e conhecimento interacional (Koch \& Elias, 2006).

Mediante o ensino da leitura na EJA, a professora, informou-nos que não recebeu nenhuma orientação metodológica sobre como atuar na referida modalidade, nem quais as orientações curriculares deve subsidiar o ensino de Língua Portuguesa. Para ela, a ausência de

\footnotetext{
${ }^{5}$ Todas as vezes que utilizarmos o substantivo, feminino, singular: professora, estaremos nos referindo à professora participe da investigação colaborativa.
} 
uma orientação pedagógica e curricular tem provocado inquietações. Afirmou que não utilizava o livro didático e que sua abordagem metodológica se dava a partir da análise linguística das referidas produções textuais dos alunos. Segundo a docente ainda, para se trabalhar com a EJA, deve-se permitir que os sujeitos alunos sintam-se copartícipes do processo de ensino e aprendizagem da Língua Portuguesa, consequentemente das práticas de leitura.

\section{ENSINO DE LÍNGUA PORTUGUESA E A DIDÁTICA DA LEITURA}

A aula de Língua Portuguesa, em qualquer nível ou modalidade de ensino, pressupõe garantir a aprendizagem dos alunos no que diz respeito aos eixos: leitura, produção de texto, oralidade e análise linguística. Para que esses sujeitos possam desenvolver habilidades e competências linguísticas sobre o uso da LP enquanto prática social, capazes de compreendê-la como língua materna, produtora de significação e integradora da organização do mundo e da própria identidade (PCNEM, 1999). No entanto, não é possível adotar uma didática da leitura que dialogue com as práticas de produção, oralidade e análise linguística, sem que o professor compreenda a língua/linguagem como forma de interação social, diálogo entre sujeitos.

Entendemos que as práticas didáticas da leitura na aula de LP, nosso objeto de investigação, representa uma oportunidade significativa de acesso do sujeito aluno da EJA à cultura letrada, sujeito esse que, muitas vezes, apresenta uma pobreza de repertório de leitura escolarizada. Mas que vivenciaram/vivenciam práticas sociais de leitura em diferentes espaços comunicativos que circulam ao reinventar o seu contexto linguístico cotidiano de interação, que se constitui por rupturas, e não somente de regularidades normativamente esperadas (Certeau, 2001).

Ao repensarmos a didática da leitura na EJA, evidenciamos em investigações anteriores (Santos, 2014; 2017) que, de fato, o leitor jovem, adulto e/ou idoso não é passivo mediante o texto. Em termos bakhtinianos, ao entendermos que na significação os elementos da enunciação são reiteráveis e idênticos cada vez que são repetidos (Bakhtin, 2009), o leitor opera um trabalho produtivo, reescreve e ressignifica os sentidos do texto. O leitor (aluno), mediante o texto, tem a possibilidade de modificar ou atribuir o sentido, faz o que bem entende, distorce, reemprega, introduz variantes, deixa de lado os usos correntes (Petit, 2010), ou seja, coloca-se no lugar de leitor. Dessa forma, qualquer texto se dar ele mesmo a ler, pelo menos em princípio, de diferentes formas (Larrosa, 2013), isso impõe e supõe

dar à leitura o estatuto de uma prática criadora, inventiva, produtora, e não anulá-la no texto lido, como se o sentido desejado por seu autor devesse inscrever-se com toda a imediatez e transparência, sem resistência nem desvio, no espírito de seus leitores. (Chartier, 2009, p. 78) 
A didática da leitura implica a mediação do diálogo leitor-texto-autor-mundo ${ }^{6}$, assim abrem-se as possibilidades para as múltiplas leituras e formas de significação do texto pelos leitores. Pois, em se tratando dos alunos da EJA, como mostramos em outros diálogos, a pobreza de acesso à cultura escrita na aula de LP, pode privar o leitor não apenas dos bens materiais de consumo, mas também da aprendizagens de outras tantas práticas de literaciais.

Mediante complexidade da escassez das práticas de leitura na escola, é preciso reconhecer também as várias práticas de leitura com as quais os jovens e adultos se engajam cotidianamente: leitura de textos bíblicos, mensagens nas redes sociais, e-mails, salas de bate-papos, portais de buscas, sites de relacionamentos, entre outros. A partir desses conhecimentos, é possível repensar as escolhas dos gêneros a serem lindos na escola, bem como a adequação dos encaminhamentos didáticos em cada uma das referidas práticas de leitura.

Os sujeitos alunos da EJA também reconhecem o potencial e a relevância da aprendizagem da leitura em suas relações sociais, como explicitaram nas falas representativas do grupo focal:

A leitura é uma porta para o conhecimento, e nos coloca em sintonia com o nosso tempo. (Aluno 3)

Leitura é onde encontro alívio, uma paz. Pois, quando isso acontece viajo nas fábulas, contos e poemas. (Aluno 11)

A leitura é uma coisa que nos ajuda mentalmente e espiritualmente. Ler é viver. (Aluno 19).

Demonstrando entender, assim, a leitura para além de fonte de conhecimento, mas associando-a a momentos de prazer. Nas práticas de leitura, ao longo e/ou por meio da interação, o sujeito recria seus referenciais e seus repertórios de leitura à medida que o texto age sobre o leitor e, o leitor age sobre o texto, num movimentum de significar o texto lido, com suas leituras possíveis.

Marcuschi (2008), ao dialogar sobre a interface entre leitura e compreensão como trabalho social, encontro entre sujeitos, forma de interação, e não atividade individual, defende que compreender não é apenas uma ação linguística ou cognitiva, é uma forma de imersão com o outro dentro de uma cultura e de uma sociedade. Pois, por meio da palavra, "defino-me em relação ao outro, isto é, em última análise, em relação à coletividade" (Bakhtin, 2009, p. 115).

Adotamos e defendemos uma didática da LP na concepção interacionista (dialógica) da língua/linguagem (Geraldi, 1986), na qual os sujeitos alunos podem se colocar como "atores", construtores sociais, sujeitos ativos que dialogicamente se constroem e são construídos no texto, considerando o próprio lugar da interação e da construção dos interlocutores.

Sendo a leitura uma atividade interativa, altamente complexa de produção de sentidos, “ler é construir uma compreensão no presente com significações que, entranhadas nas palavras,

\footnotetext{
"A palavra "mundo" metaforicamente está sendo entendida, por nós, como a representação dos saberes sóciohistóricos construídos na condição em que se existe.
} 
são dissolvidas pelo seu novo contexto - que incluem também as contrapalavras do leitor" (Geraldi, 2010, p. 103). Assim, "o sentido de um texto é construído na interação texto-sujeito e não algo que preexiste a essa interação" (Koch \& Elias, 2006, p. 11). O reconhecimento dos saberes prévios dos alunos os textos é condição necessária para que a leitura aconteça, mas não é suficiente. É preciso dar um salto qualitativo, ou seja, ultrapassar o já sabido e reconhecido para construir uma compreensão do que se lê (Geraldi, 2010).

Ao pensar o ensino da leitura, Kleiman defende que

a concepção hoje predominante nos estudos de leitura é a de leitura como prática social [...] que é subsidiada teoricamente pelos estudos do letramento. Nessa perspectiva, os usos da leitura estão ligados à situação; são determinados pelas histórias dos participantes, pelas características da instituição em que se encontram, pelo grau de formalidade ou informalidade da situação, pelo objetivo da atividade de leitura, diferindo segundo o grupo social [...]. (2004, p.14)

A leitura entendida como prática social na EJA, de modo a contribuir para a ampliação do nível de letramento dos sujeitos alunos, impõe a adoção de práticas didáticas que ressignifiquem os modelos consolidados sempre resistentes de ensino da leitura, que ultrapassem o uso do texto como pretexto e a concepção de leitura como decodificação. Mas, entendendo que no processo de leitura de um texto "o leitor opera: com o conhecimento que vão além do linguístico, com muitos outros textos, que dão ao texto um contexto" (Geraldi, 2010, p. 104). E também, para o autor ainda, em condições concretas de leitura, que incluem condições materiais de leitura, objetivos e interesses. $\mathrm{E}$, até mesmo, relações externas à prática de leitura.

Dado o exposto, os encaminhamentos didáticos de uma prática de ensino da leitura é uma opção política do professor. Nesse sentido, "o espaço da sala de aula, no tempo de aula, é lugar dominado pelo professor: fechada a porta, são os professores e os alunos que fazem a aula acontecer" (Geraldi, 2010, p. 54). Assim, adentrar na sala de aula para observar o lugar do ensino da leitura, e consequentemente dos alunos, será sempre um espaço de fomento de "novas" curiosidades epistemológicas.

\section{DA PESQUISA AO OLHAR SOBRE A DIDÁTICA DA LEITURA: PONDERANDO SOBRE OS "ACHADOS"}

Os diálogos com os corpora coletados, a saber: entrevista com a professora partícipe, sessões de estudo, observação de aulas de leitura, as sessões reflexivas e grupo focal com os alunos, mostram-nos que, apesar de sua pouca experiência na modalidade, a professora entende que as práticas de leitura devem estar articuladas às práticas de produção e de análise linguística, além de que a leitura do texto na escola implica a capacidade de evocar múltiplos sentidos entre os seus leitores. 
Durante as aulas observadas, a prática de leitura acontecia no contexto da aula. No entanto, durante as 14 (quatorze) observações, a professora didaticamente procedeu a oralização do texto, e aos alunos competia, na discussão sobre o texto, apenas à interação por meio do diálogo. Demonstrando assim, a falta de entendimento sobre o necessário diálogo do aluno com o texto, em contexto de mediação de uma prática curricular de leitura.

Embora os alunos participassem ativamente do diálogo com o texto, a professora fazia a oralização do texto, e eles não tinham acesso à materialidade escrita. Assim, o processo de pesquisa, delineia a necessidade de uma reflexão sobre o papel da mediação do professor no processo de formação do leitor jovem e adulto, e que se entenda a leitura como uma possibilidade de diálogo - interação leitor-texto-autor-mundo.

As práticas de leitura observadas revelaram que os sujeitos alunos, na tentativa de compreender o texto, apoiam-se em seus saberes sobre o mundo, sobre sua realidade, desvelam crenças, valores e identidades. Segundo a professora, eles são entendidos como sujeitos heterogêneos, que apresentam conhecimentos sobre a leitura, "cada aluno tem seu nível de leitura, de apreensão e de interesse sobre o texto" (Professora).

O corpus pesquisado, apresenta claramente que, nas aulas, há a predominância de circulação de textos do domínio discursivo literário, que abordam temáticas sociais, e, como afirmou a professora: "escolho temáticas muito próximas do cotidiano dos alunos". E os gêneros textuais que mais circularam foram: crônicas, contos, fábulas, poemas, poesias e romances (fragmentos). Esses textos foram apresentados pela professora, que tinham por propósito trabalhar os efeitos de sentido produzidos nos/pelos referidos gêneros textuais. Como afirmou um aluno: "na escola, eu só leio os textos que os professores mandam [e trazem]" (Aluno 22). Afastando-se de uma leitura como uma aprendizagem cultural polimorfa, entendida como uma aprendizagem cultural aberta a todas as outras práticas de leitura, por meio do contato com uma rede de gêneros e de práticas culturais de uso da linguagem. Desconsiderando ainda o fato de que os textos que circulam em mídias eletrônicas permitem ao leitor a validação ou a rejeição de um argumento ao apoiar-se

na consulta de textos (mas também de imagens fixas e móveis, palavras gravadas ou composições musicais) que são o próprio objeto de estudo, com a condição de que, obviamente, sejam acessíveis em forma digital. Se isso é assim, o leitor já não é mais obrigado a acreditar no autor; pode, por sua vez, se tiver vontade e tempo, refazer totalmente ou parcialmente o percurso da pesquisa. (CHARTIER, 2015, p.60)

O ingresso dos sujeitos alunos da EJA na era da textualidade eletrônica implica à adesão a uma didática da leitura que vá além da seleção de gêneros textuais impressos, e para além da leitura de textos do domínio discursivo literário. E para se propor a leitura de diferentes textos na escola, que requer também estratégias didáticas adequadas à prática da leitura, "é preciso ser 
leitor. Ninguém pode oferecer ao texto outros textos com que cotejá-lo se não for leitor" (Geraldi, 2010, p. 46).

$\mathrm{Na}$ seleção dos gêneros textuais a serem lidos pelos alunos, segundo a professora, considerava:

coisas [as temáticas sociais] que eles se identificam. Cada um [dos alunos] tem seu nível de leitura, de apreensão e de interesse pelo texto. $O$ interesse pelo texto, não é você [o professor] que desperta, mas é a relação que ele [aluno] estabelece com o texto. E está muito relacionado com o que ele [aluno] faz todo dia. O nível de apreensão, de absolvição e de negação daquilo que é apresentado [no texto] está ligado a eles [alunos], porque na verdade, eles [alunos] querem ser aceitos [na sociedade]. Assim, se a personagem se identifica com eles [alunos] é maravilhoso. Caso contrário, eles [alunos] detonam a personagem, entendeu? (Professora)

No discurso pedagógico da professora, pressupomos que ela tentava aproximar as temáticas dos gêneros literários lidos com as temáticas inferidas a partir da realidade sociocultural dos alunos com o propósito de permitir uma significativa interação entre alunos-alunos e alunosprofessora. Desse modo, "o discurso pedagógico dá a ler, estabelece o modo de leitura, tutela a leitura e a avalia” (Larrosa, 2013 p. 130). A adesão a uma concepção didática da leitura, portanto, implica à seleção do gênero textual, determina o diálogo autor-texto-leitor-mundo, controla essa relação, e define, de certo modo, o que se pode e o que deve ser lido pelo leitor, podendo dialogar com a concepção de que leitura é produção de sentidos. Concepção essa revelada pelos sujeitos da EJA quando expressam seus entendimentos sobre o texto, como já demonstramos em outras investigações.

Por meio de um olhar ainda insipiente, durante as práticas de leitura observadas, destacamos: há uma recorrência da oralização do texto pela professora; na sala de aula há a circulação dos gêneros textuais; e, com relação aos aspectos discursivos do texto, a professora chamava a atenção dos alunos sobre as relações de intertextualidade entre os textos trabalhados, conduzindo a análise para a percepção dos recursos estilísticos do texto, tais como: metáforas, repetições e comparações, dentre outros.

Entre as práticas observadas, chamou-nos a atenção à escolha e a leitura dos gêneros de autores da literatura brasileira: O povo, de Luís Fernando Veríssimo; Felicidade Clandestina, de Clarice Lispector. Esses momentos culminaram com discussões calorosas, entre os alunos, sobre os conflitos sociais vivenciados em seus cotidianos em diálogo com os sentidos produzidos nos textos lidos. Isso acontece porque para os alunos uma possibilidade didática de leitura do texto seria: "a professora contando e fazendo com que os alunos entrassem na fábula" (Aluno 11).

A postura da professora mediante as práticas de leitura espelha-se, de certa forma, nas orientações didáticas dos PCNEM, que propõem atividades de ensino da Língua Portuguesa que se apoiam na estratégia linguística de uso-reflexão-uso. Pois, em suas aulas, a professora chamava a atenção dos alunos para os usos sociais da língua, através da reflexão sobre o texto, o contexto e as práticas sociais comunicativas. 
Nas palavras da professora os discursos circulam na sala de aula, "porque tenho grandes enunciadores. Esses enunciadores, no embate por meio da linguagem em sala de aula, se efetivam enunciando suas leituras de mundo, desvendando-se: quem é quem. Ninguém sai igual depois de uma aula de leitura". Assim, entender os sujeitos alunos da EJA como enunciadores é, sobretudo, reconhecer que eles são capazes de ler a sua realidade e ressignificá-la.

Interagir com a professora sobre suas práticas de ensino da leitura, permite-nos compreender sua forma singular de entender, não só sua concepção de leitura e de linguagem, como prática social e histórica, mas como se planeja e se vivencia essa prática por meio da interação dialógica no acontecimento da aula, além do lugar do aluno leitor sujeito da EJA.

\section{PARA NÃO CONCLUIR: A COLABORAÇÃO CONTINUA}

A discussão que apresentamos demonstra que os encaminhamentos didáticos das práticas de leitura entre formar leitores e formar leitores-autores implica em uma concepção de leitura para além da oralização do texto pela professora, visto não como um ato solitário, de repetição, mas um ato político de produção por meio do diálogo autor-texto-leitor-mundo.

A investigação nos possibilitou avançar em relação aos saberes teóricos sobre a especificidade de uma didática da leitura no Ensino Médio da EJA. Entre muitos aspectos, entendendo que o leitor jovem, adulto ou idoso, através do seu conhecimento prévio, construído por meio de suas experiências escolares e não escolares, dialoga com o texto verbal e/ou não verbal, articulando ideias, ressignificando-as e se ressignificando enquanto sujeitos de linguagem.

Desse modo, temos defendido também que as aulas de leitura didaticamente deveriam ser mais interessantes de modo a permitir que os alunos, sujeitos sociais, leitores do mundo e da sua realidade, "entrassem no texto", conforme seus entendimentos e avançassem em diálogo com o autor. Desse modo, faz-se mister superar os desafios impostos aos alunos da EJA no que diz respeito a aprendizagem da leitura. Pois, esses sujeitos almejam continuar seus processos de escolarização, cursar o ensino superior, bem como inserirem-se no mercado de trabalho. $E$, nesse cenário, os alunos revelam que o professor de Língua Portuguesa é determinante na proposição e mediação de práticas curriculares de leitura mais significativas e emancipatórias, sendo essas ainda muito escassas no contexto investigado.

Salientamos que a referida investigação colaborativa, por fundamenta-se no princípio de uma pesquisa-formação, desenvolvida por meio do diálogo, universidade-escola, além de garantir o nosso olhar de pesquisadores, mediante o fenômeno investigado, práticas curriculares de leitura na escola, coloca-nos o desafio de formarmos o professor partícipe, e de sermos também ressignificados enquanto pesquisadores. 
Os achados da investigação contribuíram para o repensar do lugar das práticas de ensino da leitura na EJA e dos sujeitos alunos, como também fomentar a necessidade de formação de um grupo colaborativo no interior da escola, construindo uma cultura colaborativa que reflita sobre as práticas de leitura (situadas). E, considerando o inacabamento de uma investigação científica, novos questionamentos nos apetece: por que as práticas de leitura na escola, nem sempre, mantem relações com as práticas sociais de leitura e de escrita vividas pelos sujeitos EJA? $E$, quais motivos levam os alunos a pensar que as práticas de leitura se restringem a aula de Língua Portuguesa? Por fim, podemos reafirmar que a leitura ocupa um lugar nas aulas de Língua Portuguesa na EJA, no entanto, é preciso possibilitar um diálogo maior com a diversidade de gêneros textuais, sobretudo, os que circulam nas práticas sociais. Para isso, eis o desafio de pensarmos em "novas" práticas curriculares de ensino da leitura e de uma didática que considere a diversidade de saberes entre os sujeitos da EJA .

\section{REFERÊNCIAS}

Antunes, I. (2003). Aula de português: encontro e interação. São Paulo: Parábola Editorial.

Bakhtin, M., \& VOLOCHINOV, V. N. (2009). Marxismo e filosofia da linguagem: problemas fundamentais do método sociológico na ciência da linguagem (13. ed.) São Paulo: Hucitec.

Bogdan, R., \& BIKLEN, S. (1994). Investigação qualitativa em educação: uma introdução à teoria e aos métodos. Porto: Porto Editora.

Brasil, Ministério da Educação. Secretaria de Educação Média e Tecnológica. (1999). Parâmetros curriculares nacionais: ensino médio. Brasília: MEC/SEMTEC. 4v. . (2004). Orientações curriculares do ensino médio. Brasília, DF.

Charlot, B. (2001). Da relação com o saber: Elementos para uma teoria. Porto Alegre: Editora Artmed.

Chartier, R. (2009). A história ou a leitura do tempo. Belo Horizonte: Autêntica. . (2015). A história ou a leitura do tempo. Belo Horizonte: Autêntica.

Certeau, M. (2001). A Invenção do Cotidiano: Artes de Fazer. Petrópolis, Vozes.

Geraldi, J. W (1986). O texto na sala de aula (3 ed.) São Paulo: Ática. .(2010). A aula como acontecimento. São Carlos: Pedro e João Editores.

Ibiapina, I. M. L. M. (2008). Pesquisa colaborativa: investigação, formação e produção de conhecimento. Brasília: Liber Livro Editora.

Kleiman, A. (2004). Texto e leitor: aspectos cognitivos da leitura (13 Ed). Campinas, SP: Pontes.

Koch, I. V., \& ELIAS,V. M. (2006). Ler e compreender os sentidos do texto. São Paulo: Contexto.

Larrosa, J. (2013). Pedagogia profana: danças, piruetas e mascaradas (5 ed.). Belo Horizonte: Autêntica. . (2014). Tremores: escritos sobre experiência. Belo Horizonte: Autêntica. 
Maceió, Secretaria de Estado da Educação e do Esporte. (2012). Orientações para implantação e implementação do ensino fundamental e do ensino médio na modalidade da educação de jovens e adultos na modalidade da educação de jovens e adultos por períodos letivos semestrais na rede estadual de ensino em 2012/ Ana Márcia Cardoso... [et al.].

Marcuschi, L. A. (2008). Produção textual, análise de gêneros e compreensão. São Paulo: Parábola.

Petit, M. (2010). Os jovens e a leitura: uma nova perspectiva (2 ed.). São Paulo: Editora.

Santos, A. C. (2014) O ensino da leitura na educação de jovens e adultos: o movimentum de significar e ressignificar a prática docente em contexto de pesquisa colaborativa. Tese. (Doutorado). Universidade Federal de Alagoas, Maceió.

- (2017). Práticas cotidianas de leitura na educação de jovens e adultos no (entre)laçamento de uma cultura docente. Interdisciplinar, São Cristóvão, v. 27, jan-jun, p. 175-190.

Tardif, M. (2002). Saberes docente e formação profissional. Petrópolis: Vozes. 